\title{
World Cup 2014 - Professional Training Program for Brazilian Hotels
}

\author{
http://dx.doi.org/ijac.v4i3.1714 \\ S. A. Assis ${ }^{1}$, H. Abdalla ${ }^{2}$ and G. H. Pftischer ${ }^{2}$ \\ ${ }^{1}$ Brazilian Institute of Hospitality (IBH), Brasília, Brazil \\ ${ }^{2}$ Universidade de Brasília (UnB), Brasília, Brazil
}

\begin{abstract}
This paper presents an experience of implementing a professional training program for the Brazilian hospitality industry in the $\mathbf{1 2}$ cities that will be the headquarters of the World Cup in 2014. This project was developed in the context of the program "Welcoming Cup", of the Brazilian Ministry of Tourism, whose objective is to enable the tourism industry to attain international standards of quality in tourism services.
\end{abstract}

Index Terms-Blended learning, Professional qualification, Tourism qualification program, World Cup 2014.

\section{INTRODUCTION}

When Brazil was chosen to host the World Cup 2014, the Brazilian Ministry of Tourism created a program called "Welcoming Cup", whose goal is to enable the Brazilian tourism industry to attain international standards of quality in tourism services.

The goal of this program is to train 306,000 professionals working in the tourism front line, that is, those who will have direct contact with tourists in the World Cup 2014. This audience is composed of several segments of the tourism industry, especially food and beverage, entertainment, hotels and transportation.

Sensitization and mobilization of this contingent of professionals in a country as large as Brazil is was the main challenge identified by the Ministry of Tourism. To overcome it, partnerships were signed with trade unions that comprise the National Tourism Council, giving each one a mission to run the program in its industry.

In the hotel industry, an agreement signed with the Brazilian Institute of Hospitality, IBH, operating arm of the Brazilian Hospitality Industry Association - $\mathrm{ABIH}$, has the goal of qualifying 19,000 professionals by the end of 2013. This partnership resulted in the creation of the Hosting Virtual School - EVMH (www.evmh.com.br), adopting the use of new educational technologies, in particular, e-learning, aimed at offering vocational training courses.

In 2010, the first stage of the program, the courses were offered in 12 cities which will host the World Cup 2014: Belo Horizonte, Brasília, Cuiabá, Curitiba, Fortaleza, Manaus, Natal, Porto Alegre, Recife, Rio de Janeiro, Salvador e São Paulo. The geographical distribution of these cities is represented on the map in Figure 1.

This project involved all phases of creating a large scale training program, since the establishment of a pedagogical plan until the evaluation of the program with the propo-

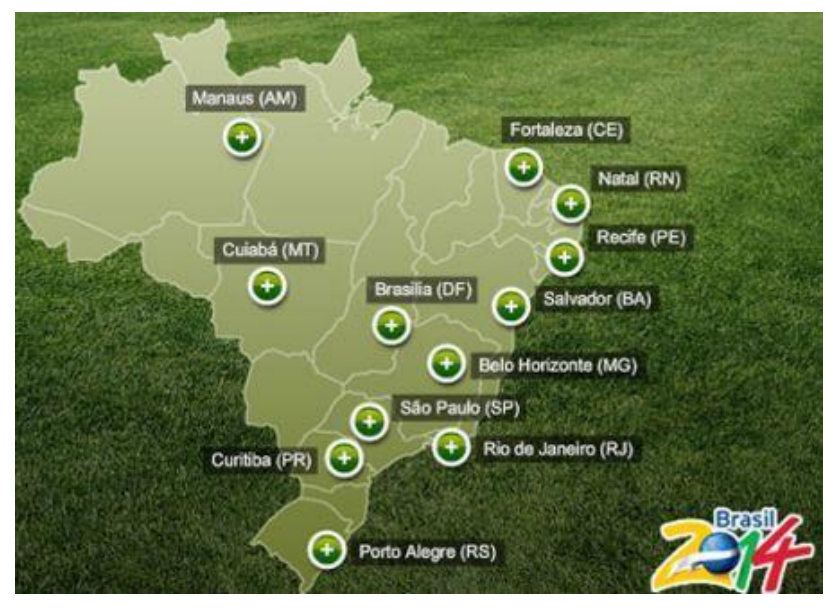

Figure 1. World Cup 2014 host cities

sition of a policy of continuing education for the hotel industry in Brazil.

This paper will present the main phases of the program and the results achieved.

\section{Project Phases}

\section{A. Pedagogical Plan}

A pedagocial plan was prepared based on a concept of learning trails, including the following aspects:

- General information;

- Training curriculum - general and specific skills;

- Theoretical basis;

- Learning trails - composition, evaluation and certification;

- Learning solutions and methods of supply.

The learning trails, focused on the functional groups to be met are: bell captain, bell boy, receptionist, housekeeping and managers. Each course, with 200 hours duration was divided into four modules. The first three modules of each course include general skills, lasting 120 hours. These three modules cover the same topics, but with specific language for each learning trail. The last module of each course, lasting 80 hours, addresses specific skills. The modules and the matters of each learning trail are presented in Table I. 
TABLE I.

LEARNING TRAILS

\begin{tabular}{|c|c|c|}
\hline Skills & Module & Matters \\
\hline \multirow[t]{3}{*}{ General } & $\begin{array}{l}\text { You, citizen, } \\
\text { and tourism } \\
\text { in Brazil }\end{array}$ & $\begin{array}{l}\text { - Ethics and citizenship } \\
\text { - Importance of tourism } \\
\text { - Cultural diversity } \\
\text { - Brazil to the world } \\
\text { - Tourist Information }\end{array}$ \\
\hline & $\begin{array}{l}\text { Communica- } \\
\text { tion and } \\
\text { relationship } \\
\text { at work }\end{array}$ & $\begin{array}{l}\text { - Communication and expression } \\
\text { - Relationship at work } \\
\text { - Service quality }\end{array}$ \\
\hline & $\begin{array}{l}\text { The hotel } \\
\text { industry } \\
\text { professional }\end{array}$ & $\begin{array}{l}\text { - Characterization of lodging facili- } \\
\text { ties } \\
\text { - Personal appearance and profes- } \\
\text { sional posture } \\
\text { - Health and Safety at work }\end{array}$ \\
\hline \multirow[t]{5}{*}{ Specific } & Bell captain & - Bell captain services \\
\hline & Bell boy & - Bell boy services \\
\hline & Receptionist & $\begin{array}{l}\text { - Receptionist services } \\
\text { - Technology applied to equipment } \\
\text { - Administrative procedures }\end{array}$ \\
\hline & $\begin{array}{l}\text { Housekeep- } \\
\text { ing }\end{array}$ & $\begin{array}{l}\text { - Housekeeping service manage- } \\
\text { ment } \\
\text { - Human resource management } \\
\text { - Technology applied to equipment }\end{array}$ \\
\hline & Manager & $\begin{array}{l}\text { - Lodging facilities management } \\
\text { - Human resource management } \\
\text { - Marketing strategies and sales } \\
\text { - Use of technological resources }\end{array}$ \\
\hline
\end{tabular}

\section{B. Educational Platform}

The portal and the online school were built and deployed in the educational platform. The web portal is used for advertising the school, the courses offered, the criteria and registration procedures.

The online school, consisting of a learning management system and a virtual learning environment, contains all the necessary resources for e-learning, from the access control via login / password, publication and access to online courses, until the recording of all accesses made by each student in each course.

This educational platform provides the following main resources:

- Web portal for dissemination of the training program;

- Publication of courses with their respective evaluation items;

- Enrollment of students, giving them a login and password that will ensure them access to the virtual learning environment and courses contents;

- Resources for tutors and managers perform their activities;

- Monitoring and tracking of students performance;

- Virtual library services, webmail and forum.

The educational platform was hosted in a data center with all necessary infrastructures, providing the conditions for completion of courses for all participants.

\section{Teaching material}

The teaching material for the five courses was designed to comply with the pedagogical plan. This phase included the preparation of content, instructional design, e-learning implementation, testing and publishing in the educational platform, as well as layout and production of printed material with all the content covered by the courses.

The online material was published in the educational platform for access by students and the printed material was packed in a bag, which also included a notepad and a pen, composing the student kit.

\section{Maintenance and Technical Support}

Once deployed the educational platform, a team of technically qualified professionals has been allocated to provide the services of corrective, adaptive and evolution software maintenance.

The technical support service was provided to students by a team of six professionals. This team provides support, via Internet and telephone in every weekday, from 8 am to $18 \mathrm{pm}$.

The technical support service for tutors and coordinators was conducted by a team of two professionals, via Internet and telephone in every weekday, from 8 am to 18 pm.

Besides these technical support services, were provided at school, to make the records and provide all students with academic information.

\section{E. Mobilization}

The mobilization was one of the most critical stages of the project and required a large media effort. The strategy to ensure compliance of managers and professionals in the hotel sector was implemented through the ABIHs in each state.

In each of the 12 cities that will host the World Cup 2014, was asked the president of the local ABIH, to invite the hotels managers for a lecture to present the "Welcoming Cup" program. These presentations were conducted by a team of lecturers, who presented the project, the courses, the methodology and criteria for participation.

Since the courses are free, a mutual cooperation has been required from the hotels, as follows:

- Designate a manager of the hotel to make communication with the EVMH, select and direct their employees during the courses;

- Provide adequate space and computers with internet access for their employees during the courses;

- Provide 2 to 5 hours per week per employee on company time to conduct courses.

To support the work of the promotion team, banners, folders and posters were produced. The banners were displayed at the headquarters of the local ABIHs and were also used in the event of mobilization as well as in all the workshops during the offering of courses. The folders were distributed in the mobilization events and in the hotels. The posters were posted on bulletin boards in the hotels. This material has been very useful to publicize the program and to strengthen the program mark in the hotel industry.

After completion of sensitization lectures, appeared on the scene the local coordinators and the advisers hired 
locally in each city to visit the hotels, enhancing the action of the lecturers and registering the professionals in the courses. The remuneration policy of this team includes a bonus based on the number of participants enrolled.

A call center was implemented to support the mobilization actions, especially to confirm participation of hotels managers in the lectures and to strengthen the contacts with managers to encourage them to enroll their employees in the program.

This mobilization effort had been conducted over three months and resulted in the registering of 7,133 professionals, surpassing by more than 2,000 the number of vacancies previously established.

\section{$F$. Implementation of training program}

The first stage of the program, held in 2010, provided for the supply of 4,115 vacancies distributed among the 12 destinations. This step included since the registration until the certification of the participants graduated. This was the most critical part of the project, because it's huge the effort to keep students motivated and participating in the program until the end. To this end, several actors were involved. In the following topics will be listed and described the roles of each one.

\section{1) Student}

The student is the central figure of the educational process, and its characteristics and learning styles guided the development of the educational activities offered. The main roles of the EVMH student are:

- Participate actively in the construction of knowledge, contributing with ideas, criticisms and solutions that can enrich the learning process;

- Make constant use of the educational platform to develop new knowledge and to share ideas and / or experiences developed;

- Share tacit knowledge about products, processes or services on which he has developed a particular way of improving results;

- Assume responsibility for the pursuit of its ongoing development.

\section{2) Hotel Human Resource Manager}

The owner of the hotel or someone designated, usually the human resources manager, acting as a leading educator. It is an important learning agent, since it is his responsibility ensures the consolidation of the learning process in the team of his company. It is done either through the dissemination of knowledge and strategies, encouraging the self development and sharing of knowledge between the hotel team, by the careful indication of employees to participate in educational activities, providing and receiving feedback, among others. The main roles for these managers are:

- Indicate their company's employees for participation in the training program;

- Manage, guide and mediate the development of the employees of their companies;

- Follow the development and the training progress of their employees through the monitoring of their staff in the educational platform.

\section{3) Continuing Education Team}

It is the central program team, which includes the General Coordinator, the Academic Coordinator and the courses Coordinators. Their main assignments are described as follows.

a) General Coordinator

The General Coordinator is responsible for overall coordination and operation of the program, with the following responsibilities:

- Oversee all operational-level actions to ensure compliance with the educational guidelines established;

- Contact program staff systematically in order to ensure unity of action and institutional support necessary for quality of courses;

- Track and monitor the dropout rate, seeking for permanent solutions to reduce it;

- Evaluate the performance of local coordinators and support them in their actions, providing the right conditions for them to do their activities;

- Plan the implementation of local meetings, providing all necessary resources to carry out these workshops;

- Prepare monthly reports covering all actions performed in the program;

- Gather and consolidate, along with the other coordinators, suggestions for improvements to the training program;

- Record all relevant experiences of the program in order to consolidate a policy of continuing education for the segment of hotels.

\section{b) Academic Coordinator}

Responsible for coordinating the education program and the achievement of the issues with the following responsibilities:

- Oversee all shares on the pedagogical level to ensure compliance with the educational guidelines established by the pedagogical plan;

- Conduct meetings with the courses coordinators to point out all actions engendered in the training program, on the tactical level;

- Clarify the coordinators and tutors on the course organization, the tutoring system presented in the curricular structure, concepts, methods, evaluation system and the learning environment;

- Monitor the flow of information between course coordinators and tutors;

- Monitor the dropout rate, proposing and implementing actions to reduce it;

- Evaluate the performance of the courses coordinators;

- Assist local coordinators in monitoring the performance of their tutors;

- Assist coordinators and tutors in the implementation of workshops;

- Coordinate and planning the delivery of the modules of courses and related activities;

- Prepare monthly reports covering all actions performed in the program. 


\section{c) Courses Coordinators} for:

- Monitor student performance and motivating them, making the courses interesting to them;

- Monitoring the development of the course, adopting strategies to avoid evasion;

- Manage, in the educational dimension, the teaching process to ensure quality of the course;

- Propose additional activities to those provided in the course in order to enhance their quality and / or redirect the activities that demonstrably not prove adequate;

- Establish permanent forms of articulation with tutors and between them, aimed at the educational unit of the teaching-learning process;

- Orient tutors about the theoretical and methodological assumptions, the educational concepts and pedagogical theories and tools for e-learning and assessment adopted in the courses;

- Enlighten students about the organization of the course, the tutoring system presented in the curriculum framework, concepts, methods, evaluation system and the learning environment;

- Monitor the flow of information between students and tutors;

- Accompany the submission of evaluations from participants to tutors and ensure the return of corrections;

- Pay attention to dropout rate, proposing and implementing actions to reduce it.

\section{4) Local Coordinator}

Local coordinators were selected in partnership with the local $\mathrm{ABIH}$ in each destination, to ensure greater involvement of these entities with the program. The selection of these coordinators took into account the following profile requirements:

- Graduated, preferably in tourism / hospitality, with an emphasis on lodging facilities or related fields;

- Broad industry knowledge of lodging in the region;

- Professional training experience in the hotel sector;

- Experience in training and managing teams;

- Experience with Internet, social networks and Microsoft Office;

- Good command of Portuguese (oral and written communication);

- Ease of communication and persuasion.

The responsibilities of the local coordinators are:

- Coordinate with the entities of the hospitality segment of their destiny to publicize the program for the sector;

- Disseminate the courses offered for the target audience and clarify the methodology, the length of courses and the dedication needed to achieve the target;

- Sensitize the hotel sector to the importance of qualifications of its professionals, as well as clarify the counterparts of the establishments to participate in the program;

- Conduct lectures for managers of lodging facilities of the destination in order to present the program and courses offered;

- Enter along with the hotels, participants in the educational platform.

- Play, along with the team of tutors, local workshops;

- Pay attention to dropout rate, proposing and implementing actions to reduce it.

- Assist in evaluating the performance of tutors under its responsibility;

- Implement, together with the tutor, the redemption process of the students who did not achieve performance on the steps of the courses;

- Spoon feedback from students and managers to improve the teaching material and courses;

- Communicate the General Staff all facts or circumstances of his knowledge that might compromise the success of the program.

\section{5) Tutor}

In the model proposed in the EVMH program, the tutor has a key role, since the learning process of participants cannot be restricted to the provision, for study, of a set of educational solutions, even with reflective and interactive activities via Internet. The tutor is crucial in the quest for an interactive relationship with their students, supporting them on their path of building knowledge and skills development techniques.

The tutors also acted with the role of instructors, since they reside in the destinations served, making shifts to answer questions at the place of students' work. These professionals have the following responsibilities:

- Accompany and support the participants in their learning process, identifying the differences between their trajectories, respecting their own rate, valuing their achievements, encouraging exchanges between students, seeking to integrate them and helping them to meet the challenges that requires individualized instruction;

- Create routines for monitoring student learning, encouraging them throughout the process, visiting them regularly at their workplaces;

- Evaluate the route of the students in the course, from the ethical commitment to their progress, promoting complementary actions that allow the overcoming of difficulties;

- Participate in the implementation of workshops, ensuring active participation of all actors involved in the process;

- Promote the use of discussion forums, with the aim of encouraging socialization, the interaction between participants and the formation of a learning community;

- Monitor and evaluate the activities of evaluative learning modules (forums and other tasks);

- Monitor the access of students to the platform. If they are not interacting, make contact by phone or email, in order to check the possible causes of absence. 
Given the program audience profile, in many situations it has been necessary for the tutor to visit their students in their workplaces in order to support them and encourage them in their studies, as well as performing the weekly activities planned. Only with this personal training model, avoidance could be reduced to the levels envisaged in the project. Therefore, in the remuneration of the tutor was included a monthly complement for displacements.

Moreover, it was included in the remuneration of the tutors a bonus for meeting performance goals based on the number of students graduated, which made them to dedicate most of their time to the program.

\section{G. Workshops}

The courses plan provided for the holding of four workshops, lasting four hours each, with an average of 60 students each.

The first workshop was held at the beginning of the course, when were made the presentation of the local team, the methodology and the learning materials, delivered on this occasion. Also in this first meeting, the educational platform was presented, in which the participants made their first contact.

In the other three subsequent meetings, held at the end of the first, second and third study guides, workshops were held, when studied contents were consolidated and the motivation of participants was promoted.

\section{H. Graduation and Certification}

At the end of the program, successful students received a certificate in the form of a plastic card, shaped like a credit card, branded the Program "Welcoming Cup". This model of certificate has been highly praised by participants and hoteliers. The front part of this certificate is shown in Figure 2.

A graduation ceremony, in which certificates were delivered, was performed in each of the 12 destinations. These ceremonies were the most exciting point of the whole process, because the students made several statements praising the program, thanking for the opportunity of taking part of it and showing motivation and interest to continue developing professionally.

\section{Monitoring, Evaluation and Program Improvement}

The educational activities of this program were evaluated at the following levels:

- Reaction;

- Learning;

- Performance Impact.

At the reaction level, it was measured the impact of the educational action searching for information about: acceptance of the program, the appropriateness of learning strategies applied, the appropriateness of the course duration, the perception on the performance of instructors on the infrastructure available and also on the applicability and usefulness of the content covered in the educational action.

At the learning level, it was observed how much the learning goals were reached by participants and how much they learned what was expected. It was verified the level of performance in relation to the goal of learning of each module in various dimensions such as: participation,

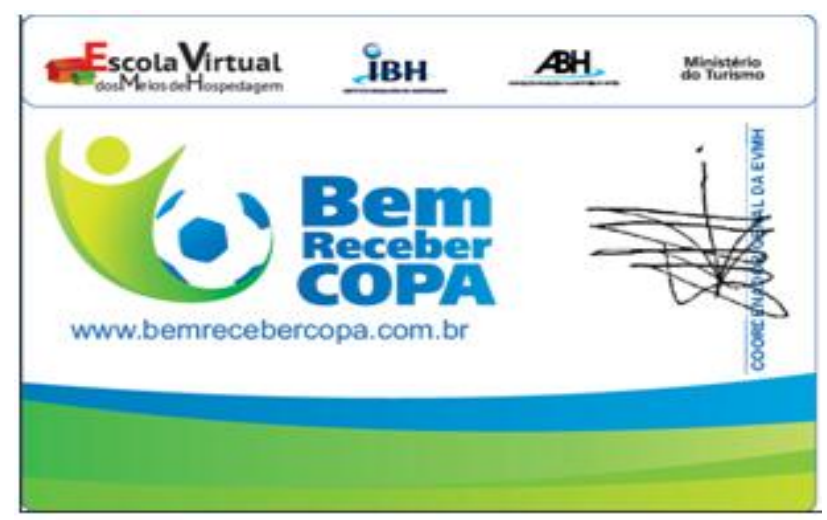

Figure 2. Certificate front part

knowledge in written evaluation, performing activities, among others.

The performance impact, the main goal of the program, will measure the impact of the educational action in professional performance in their daily activities. The instruments of this evaluation should be answered by managers and program participants. It will be linked to learning goal set for the educational action. Their results will indicate how much of the knowledge, skills, attitudes and / or behaviors expected the participants have adopted effectively.

This stage of monitoring and evaluation was developed through:

- Development of tools for evaluating and monitoring the program;

- Application of evaluation and monitoring tools;

- Data analysis;

- Elaboration of proposals for adjustments and improvements in the program, with the proposition of a policy of continuing education for the Brazilian hospitality industry.

These activities were developed by a multidisciplinary team comprised of professionals with academic background and extensive experience in the areas of hospitality, education, labor and organizational psychology, statistics, communication and human resources with focus on the hospitality industry.

The program has also been evaluated by an external institution, the Fundação Getúlio Vargas - FGV, in a survey entitled "Survey with participants in the first offering of the Program Welcoming Cup" in which, on a scale of 1 to 4 , with 1 - very bad 2 - poor, 3 - satisfactory, 4 - very good, $30 \%$ of respondents rated the course as satisfactory and $69.4 \%$ assessed as very good.

\section{RESUlTS}

In the first stage of the program for the hospitality industry, held in 2010 in the 12 host cities for the World Cup 2014, 5,315 professionals were registered. Of these, 4,364 participants have completed the courses, i.e., $82 \%$ completion rate. Table II shows these numbers for each course. 
TABLE II.

NUMBER OF STUDENTS PER COURSE

\begin{tabular}{|l|c|c|}
\hline \multicolumn{1}{|c|}{ Course } & Enrolled & Graduated \\
\hline Bell captain & 143 & 108 \\
\hline Bell boy & 476 & 389 \\
\hline Receptionist & 1,854 & 1,499 \\
\hline Housekeeping & 1,029 & 865 \\
\hline Manager & 1,813 & 1,503 \\
\hline Total & $\mathbf{5 , 3 1 5}$ & $\mathbf{4 , 3 6 4}$ \\
\hline
\end{tabular}

IV. CONCLUSION

The main factors that contributed to achieving these excellent results were:

- Effective participation of local ABIHs in the process of sensitization and mobilization;

- Courses taken at workplace during working hours;

- Weekly progress monitoring of each student;

- Permanent contact with the managers of hotels to rescue students;

- Tutors and coordinators visit to hotels to support the rescue of students;

- Enhancing students' motivation in the local workshops;

- Fixed and variable remuneration for coordinators and tutors on the basis of student performance.

The methodology of distance education with the use of e-learning proved to be correct, considering the evaluation of participants and the results achieved. Of the 5,315 enrolled, 4,364 participants have completed the courses, i.e., the program had a dropout rate of only $18 \%$, an excellent index for this mode of teaching.

The graduation ceremonies were held in the 12 cities with large student participation. In all events it became clear through the testimonies of the students and the speeches of the speakers, the success of the program performed. Everyone praised the initiative and requested to be replicated in future years, thus reaching a larger number of professionals in the hotel industry.

Given these results, it can be stated that the program promoted the achievement of the following benefits:

- Raising self-esteem of participants;

- Expansion of the capacity of participants to provide tourist information to customers;

- Improving the quality of services provided by participating hotels;

- Development of a culture of continuing education by the hotel workers.

This excellent result achieved in 2010 established the benchmarks for implementing the second phase of the Program in 2011, with a target of 15000 professionals, covering 33 destinations which encourage tourism in Bra- zil, among them, the 12 cities which will host the World Cup 2014.

\section{ACKNOWLEDGMENT}

During the 2010 hundreds of professionals contributed significantly to the achievement of this qualification program. All deserve our thanks. Some will be quoted by name, because without them this program would not have existed. We will begin by Dr. Regina Cavalcante and her technical team of the Ministry of Tourism, where this program was designed; César Gonçalves, from IBH, which has always guided wisely this project implementation; Enrico Fermi, on whose behalf we thanks all the Presidents of the state ABIHs the support in disseminating and implementing the program; Ciro Carneiro Hasslocher, on whose behalf we thanks the entire CETEB team; Simone Santos Melo, tireless in the overall coordination of EVMH; Carla Tenser and her team of content writers; Raphaela Paiva and her development team; Ezequiel Neves, EVMH academic coordinator; Carolina Almeida de Souza Lobo, on whose behalf we thanks all the courses coordinators; Janaina Baggio and Anivalda Bezerra Ribeiro, on whose behalf we thanks all our local coordinators; Francisco Tommy Freund, on whose behalf we thanks all the tutors; Patrícia Carvalho e Rafael Silveira, responsible for EVMH logistics; Elton Gomes, on whose behalf we thanks the Information Technology staff; Ana Carolina Barreto, on whose behalf we thanks the entire telemarketing and technical support teams.

\section{AUTHORS}

S. A. Assis is with Brazilian Institute of Hospitality, IBH, Brasília, DF 70000 Brazil, (e-mail: silvone.assis@gmail.com).

H. Abdalla is with the Electrical Engineering Department, University of Brasília, Brasília, DF 70000 Brazil, (e-mail: abdalla@ene.unb.br).

G. H. Pfitscher is with the Electrical Engineering Department, University of Brasília, Brasília, DF 70000 Brazil, (e-mail: gerson@unb.br).

This work was supported by the Ministry of Tourism of Brazil and the Brazilian Institute of Hospitality, IBH. This article is an extended version of a presentation at ICELW 2011 - The International Conference on Elearning in the Workplace, held from June 8th-10th, 2011 at Columbia University, New York, NY, USA. Received June $21^{\text {st }}, 2011$. Published as submitted by the authors August $5^{\text {th }}, 2011$. 